UDC 615.282-322

DOI: $10.15587 / 2519-8025.2021 .241538$

\title{
RESEARCH OF ANTIULCER ACTIVITY OF DIETARY CONCENTRATE OF PHENOLIC COMPOUNDS OF APPLES ON MODELS OF EXPERIMENTAL ULCER IN RATS
}

\author{
Liubov Galuzinska, Vira Kravchenko, Ganna Kravchenko, Tetiana Briukhanova, \\ Victoriia Fylymonenko
}

Medicinal plants have been widely used in the treatment of many diseases, especially in the gastroenterology, given that the use of synthetic antiulcer drugs in clinical practice often leads to the development of various kinds of side effects and, accordingly, have a large list of contraindications.

The aim of this experimental work was the study of the antiulcer activity of the food concentrate of phenolic compounds of apples on the models of experimental ulcers in rats.

Materials and methods. The studies included two stages, which were carried out on models: stage I-a model of alcohol-prednisolone stomach ulcer in rats, stage II - a model of indomethacin stomach ulcer in rats in accordance with the methodological recommendations of the SEC of the Ministry of Health of Ukraine. The studied concentrate was administered in a dose based on the total content of polyphenols - $9 \mathrm{mg}$ per $100 \mathrm{~g}$ of weight. Quercetin at a dose of $5 \mathrm{mg} / \mathrm{kg}$ and ranitidine at a dose of $20 \mathrm{mg} / \mathrm{kg}$ were used as reference drugs. After replicating the models, a macroscopic examination of the gastric mucosa was carried out and the content of TBA-reactants and reduced glutathione in the stomach homogenate was determined.

Results. Under pathological conditions, the therapeutic effect of the food concentrate of phenolic compounds of apples and reference drugs was comparable in terms of the degree of ulcer defect. It was proved that food concentrate of phenolic compounds of apples and reference drugs inhibit the course of lipid peroxidation reactions and support endogenous antioxidant defense systems.

Conclusions. The obtained results make it possible to recommend a further study of the food concentrate of phenolic compounds of apples for the creation of a pharmaceutical preparation on its basis. A promising area of application of this concentrate will be the prevention and treatment of gastric ulcer

Keywords: stomach ulcer, food concentrate of phenolic compounds of apples, lipid peroxidation, antioxidant system, antiulcer activity

\section{How to cite:}

Galuzinska, L., Kravchenko, V., Kravchenko, G., Briukhanova, T., Fylymonenko, V. (2021). Research of antiulcer activity of dietary concentrate of phenolic compounds of apples on models of experimental ulcer in rats. ScienceRise: Biological Science, 3 (28), 10-14. doi: http://doi.org/10.15587/2519-8025.2021.241538

(C) The Author(s) 2021

This is an open access article under the Creative Commons CC BY license hydrate

\section{Introduction}

Medicinal plants have been widely used in the treatment of many diseases, and nowadays it is difficult to overestimate the importance of herbal medicines for medical practice $[1,2]$. These drugs are especially important in the field of gastroenterology, given that used in clinical practice, synthetic antiulcer drugs often lead to the development of various side effects and, accordingly, have a large list of contraindications [3, 4].

According to the scientific literature and the results of our own research, it can be assumed that the substance of phenolic compounds of apples, with low toxicity and a wide range of pharmacological properties, can be very useful for correcting those pathogenesis that are characteristic of gastropathies of different genesis [5, 6]. The lack of literature data and any experimental information on the gastroprotective properties of the sub- stance from the phenolic compounds of apples is a good reason for this study [7].

The aim of this experimental work was to study the antiulcer activity of food concentrate of phenolic compounds of apples in models of experimental ulcers in rats.

\section{Materials and methods}

The experimental part of the work was carried out in autumn 2020 on the basis of the educational and scientific training center of medical and biological research of the Educational and Scientific Institute of Applied Pharmacy of the National University of Pharmacy. As the object of the study used food concentrate of phenolic compounds of apples - a functional food product (developed at the Department of Pharmacognosy of the National University of Pharmacy under the direction of prof. Koshovoy O. M., Ukrainian patent for utility model 107825 
Ukraine IPC A23L 2/08 (2006.01) "Method obtaining a food concentrate of phenolic compounds of apples No. 12"; appl. 10.12.2015; publ. 24.06.2016. - 3 p.).

The experiment was performed on purebred white male rats weighing 180-220 g, complied with ARRIVE recommendations and was performed in accordance with the British Animal Act (scientific procedures) of 1986, guided by EU Directive 2010/63/EU on the protection of animals used for scientific purposes.

The study included two stages, which were conducted on models: Phase I - model of alcoholprednisolone gastric ulcer in rats, Phase II - model of indomethacin gastric ulcer in rats in accordance with the guidelines of the SEC of the Ministry of Health of Ukraine [8]. The test concentrate was administered in a dose based on the total content of polyphenols $-9 \mathrm{mg}$ per $100 \mathrm{~g}$ of weight. Quercetin at a dose of $5 \mathrm{mg} / \mathrm{kg}$ and ranitidine at a dose of $20 \mathrm{mg} / \mathrm{kg}$ were used as comparison drugs.

In the first phase of the study, alternative changes in the stomach in animals caused the combined coadministration of $80 \%$ ethyl alcohol at a dose of $0.8 \mathrm{ml}$ per $100 \mathrm{~g}$ of body weight and prednisolone at a dose of $20 \mathrm{mg} / \mathrm{kg}$, which led to inhibition of phospholipase activity and ulceration. The study was performed on white nonlinear rats weighing 180-200 g. 1 hour before the introduction of aggressive agents and 3 hours after the study extract was administered at a dose of $50 \mathrm{mg} / \mathrm{kg}$ and comparison drugs quercetin and ranitidine. A day later, the animals were decapitated under ether anesthesia, removed the stomachs and performed macroscopic analysis.

It is known that the side effect of most nonsteroidal anti-inflammatory drugs is the development of gastric ulcer and is common with indomethacin. In this regard, at the next stage of the study, the ulcer was modeled by a single intraperitoneal injection of indomethacin at a dose of $20 \mathrm{mg} / \mathrm{kg}$ in rats weighing 200-220 g.

The animals were then injected with the test extract and reference drugs for three days. After that, under ether anesthesia, rats were removed from the experiment and performed a macroscopic examination of the stomach.

Then calculated the antiulcer activity of the test substances according to the formula:

$$
\mathrm{A}=100 \%-(\mathrm{Cd} / \mathrm{Ck} \bullet 100) \text {, }
$$

where $\mathrm{A}$ - antiulcer activity, \%;

$\mathrm{Ck}$ - the degree of damage in points in the group of control animals;

$\mathrm{Cd}$ - the degree of damage in points in the group of studied animals;

Using biochemical methods of analysis in gastric homogenate, indicators were determined that generally characterize the balance of the LPS process in accordance with and counted the number of ulcers. The concentration of TBA-rectants and reduced glutathione (GSH) was determined in gastric homogenates [9].

The results were processed statistically, the significance of differences for groups with normal distribution of the trait was calculated using the parametric Student's t-test. The discrepancy was considered statistically significant at $\mathrm{P} \leq 0.05$ [10].

\section{Results}

At the first stage of the study, gastric ulcer was reproduced by the introduction of two aggressive factors ethyl alcohol and prednisolone.

The obtained data, which are presented in Table 1 showed that in control animals there were numerous ulcers and hyperemia of the gastric mucosa (Table 1). The study of the content of lipid peroxidation in the gastric homogenate showed that the level of TBA reactants significantly exceeds this figure in intact animals by 2.1 times (Table 2). The concentration of reduced glutathione was significantly lower than in the group of intact animals almost 2 times, which indicates a weakening of antioxidant protection as a result of the inflammatory process.

Table 1

Antiulcer activity of food concentrate of phenolic compounds of apples and comparison drugs in the conditions of alcohol-prednisolone gastric ulcer $(\mathrm{M} \pm \mathrm{m}, \mathrm{n}=7)$

\begin{tabular}{|c|l|c|c|}
\hline No. & \multicolumn{1}{|c|}{ Group of animals } & Degree of damage, points & $\begin{array}{c}\text { Antiulcer } \\
\text { activity, } \%\end{array}$ \\
\hline 1 & Control pathology & $4.57 \pm 0.35$ & - \\
\hline 2 & $\begin{array}{l}\text { Food concentrate of phenolic compounds of ap- } \\
\text { ples } \\
9 \mathrm{mg} \text { of polyphenols per } 100 \mathrm{~g} \text { of weight }\end{array}$ & $2.14 \pm 0.54^{*}$ & 53.1 \\
\hline 3 & Quercetin, $5 \mathrm{mg} / \mathrm{kg}$ & $2.42 \pm 0.46^{*}$ & 47.0 \\
\hline 4. & Ranitidine $20 \mathrm{mg} / \mathrm{kg}$ & $1.71 \pm 0.55$ & 62.6 \\
\hline
\end{tabular}

Note: * the difference is significant in relation to the control pathology $(p \triangleleft 0.05) ; n$ is the number of animals in the group

The use of food concentrate of phenolic compounds of apples at a dose of $9 \mathrm{mg}$ of polyphenols per $100 \mathrm{~g}$ of weight was accompanied by a decrease in the degree of ulcer defect by $53.1 \%$ (Table 1). Inhibition of the process of lipid peroxidation under the influence of the test substance was confirmed by a significant decrease in the serum content of TBA reactants (1.6 times), and an increase in reduced glutathione (1.5 times).
The results of the study of antiulcer activity of the comparison drugs of quercetin and ranitidine show that their effect was $47 \%$ and $62.6 \%$, respectively (Table 1).

The level of TBA reactants in gastric homogenate in the group of animals treated with quercetin was significantly higher than in control rats 1.4 times. On the part of the components of antioxidant protection with the use 
of quercetin, there was a normalization of the corresponding indicator of reduced glutathione.

After administration of ranitidine to experimental animals, a significant improvement in LPS and antioxi- dant protection was also observed in gastric homogenate. The content of TBA reactants was 1.3 times lower than in the control pathology group, while the level of reduced glutathione increased 1.3 times (Table 2).

Table 2

The effect of food concentrate of phenolic compounds of apples and comparison drugs on lipid peroxidation and antioxidant system in gastric homogenate in alcohol-prednisolone gastric ulcer in rats $(\mathrm{M} \pm \mathrm{m}, \mathrm{n}=7)$

\begin{tabular}{|c|l|c|c|}
\hline No. & \multicolumn{1}{|c|}{ Group of animals } & TBA reactants, $\mathrm{nmol} / \mathrm{g}$ & $\mathrm{GSH}, \mu \mathrm{mol} / \mathrm{g} \%$ \\
\hline 1 & Intact & $2.15 \pm 0.11$ & $5.90 \pm 0.39$ \\
\hline 2 & Control pathology & $4.55 \pm 0.15^{*}$ & $2.98 \pm 0.51^{*}$ \\
\hline 3 & $\begin{array}{l}\text { Food concentrate of phenolic compounds } \\
\text { of apples } \\
9 \mathrm{mg} \text { of polyphenols per 100 g of weight }\end{array}$ & $2.92 \pm 0.12 * / * *$ & $4.58 \pm 0.49 * / * *$ \\
\hline 3 & Quercetin, 5 mg/kg & $3.25 \pm 0.09 * / * *$ & $4.78 \pm 0.57 * / * *$ \\
\hline 4. & Ranitidine $20 \mathrm{mg} / \mathrm{kg}$ & $3.43 \pm 0.32 * / * *$ & $3.90 \pm 0.39 * / * *$ \\
\hline
\end{tabular}

Note: $*$ - the difference is significant in relation to intact $(p \unlhd 0.05) ; * *-$ the difference is significant in relation to the control pathology ( $\leq \leq 0.05)$; $n$ is the number of animals in the group

Due to the fact that the side effect of most nonsteroidal anti-inflammatory drugs is the formation of gastric ulcer, the study of the effect of dietary concentrate of apple phenolic compounds on the course of ulcers caused by indomethacin, was the next step in our research.

Three days after the use of indomethacin in animals of the control pathology group, ulcers and severe hyperemia of the mucous membrane were observed (Table 3).
Determination of lipid peroxidation and antioxidant system in gastric homogenate showed that the level of TBA reactants significantly exceeds this value in intact animals by 2.4 times, and the concentration of reduced glutathione was significantly reduced by 2.3 times (Table 4). This may indicate the activation of the mechanisms of ulcerogenesis, which was marked by inhibition of the non-enzymatic link of antioxidant protection in rats of the control pathology group.

Table 3

Antiulcer activity of food concentrate of phenolic compounds of apples and comparison drugs under conditions of indomethacin gastric ulcer in rats $(M \pm m, n=7)$

\begin{tabular}{|c|l|c|c|}
\hline No. & \multicolumn{1}{|c|}{ Group of animals } & Number of ulcers & Antiulcer activity, \% \\
\hline 1 & Control pathology & $5.5 \pm 0.74$ & 49.1 \\
\hline 2 & $\begin{array}{l}\text { Food concentrate of phenolic compounds } \\
\text { of apples } \\
9 \mathrm{mg} \text { of polyphenols per } 100 \mathrm{~g} \text { of weight }\end{array}$ & $2.8 \pm 0.19^{*}$ & 36.4 \\
\hline 3 & Quercetin, $5 \mathrm{mg} / \mathrm{kg}$ & $3.5 \pm 0.44^{*}$ & 54.5 \\
\hline 4 & Ranitidine $20 \mathrm{mg} / \mathrm{kg}$ & $2.5 \pm 0.36^{*}$ & \\
\hline
\end{tabular}

Note: $*$ - the difference is significant in relation to the control pathology $(p \unlhd 0.05) ; n$ is the number of animals in the group

Table 4

The effect of food concentrate of phenolic compounds of apples and reference drugs on lipid peroxidation and antioxidant system of white rats in indomethacin gastric ulcer $(M \pm m, n=7)$

\begin{tabular}{|c|l|c|c|}
\hline No. & \multicolumn{1}{|c|}{ Group of animals } & TBA reactants, nmol/g & GSH, $\mu \mathrm{mol} / \mathrm{g} \%$ \\
\hline 1 & Intact & $2.15 \pm 0.11$ & $5.90 \pm 0.39$ \\
\hline 2 & Control pathology & $5.25 \pm 0.90^{*}$ & $2.54 \pm 0.61^{*}$ \\
\hline 3 & $\begin{array}{l}\text { Food concentrate of phenolic compounds } \\
\text { of apples } \\
9 \mathrm{mg} \text { of polyphenols per } 100 \mathrm{~g} \text { of weight }\end{array}$ & $3.12 \pm 0.25^{* / * *}$ & $4.98 \pm 0.46^{* / * *}$ \\
\hline 3 & Quercetin, $5 \mathrm{mg} / \mathrm{kg}$ & $3.44 \pm 0.37 * / * *$ & $4.86 \pm 0.37^{*} / * *$ \\
\hline 4. & Ranitidine $20 \mathrm{mg} / \mathrm{kg}$ & $3.98 \pm 0.52^{*}$ & $3.85 \pm 0.49^{*} / * *$ \\
\hline
\end{tabular}

Note: $*$ - the difference is significant in relation to intact $(p \leq 0.05) ; * *-$ the difference is significant in relation to the control pathology ( $\leq \leq 0.05) ; n$ is the number of animals in the group

The administration of food concentrate of phenolic compounds of apples significantly reduced the formation of ulcers in 2 times, edema and redness of the gastric mucosa on macroscopic examination were almost not observed (Table 3). The antiulcer activity of the extract "food concentrate of phenolic compounds of ap- 
ples" was $49.1 \%$. The level of lipid peroxidation and the antioxidant system tended to normalize (Table 4). There was also a significant 2-fold increase in glutathione protection in gastric homogenate. The level of TBA reactants was 1.7 times lower than in animals of the control pathology group.

The antiulcer activity of the comparison drugs was quite high. Inhibition of the LPS process under the influence of quercetin and ranitidine was accompanied by a significant reduction in the values of control pathology in the content of TBA reactants in the gastric homogenate (1.5 and 1.3 times, respectively). On the part of the antioxidant defence system, quercetin and ranitidine showed a 1.9-fold and 1.5-fold increase in the level of reduced glutathione, respectively.

\section{Discussion of research results}

Experimental data show that the dietary concentrate of phenolic compounds of apples in pharmacological activity is somewhat inferior to the comparison drug ranitidine, but more effectively affects the normalization of the studied biochemical parameters (TBA reactants and reduced glutathione) due to antioxidant properties [7]. Indicators of antiulcer activity similar to the test substance and the effect on the change of the content of TBA reactants and reduced glutathione were observed with the introduction of quercetin, which is one of the active components of the concentrate.

Studies of the antiulcer activity of food concentrate of phenolic compounds of apples were conducted for the first time, and the data obtained on this effect were confirmed by previous studies of substances from plant raw materials $[11,12]$. But the results of the effectiveness of food concentrate were confirmed by some biochemical indicators: a decrease in the content of TBA reactants and an increase in the level of reduced glutathione in the gastric homogenate.

Study limitations. The obtained results do not fully reflect the mechanism of antiulcer activity and there is a need for further study of this aspect.
Prospects for further research. After a series of studies and results on acute and chronic toxicity, it will be possible to recommend further study of food concentrate of phenolic compounds of apples to create a pharmaceutical based on it, which will be used in the prevention and treatment of peptic ulcer disease.

\section{Conclusions}

Under conditions of pathology, the therapeutic effect of food concentrate of phenolic compounds of apples and comparison drugs (quercetin and ranitidine) was comparable in terms of the degree of ulcer defect. In the model of alcohol-prednisolone ulcer, the antiulcer activity of food concentrate was $53.1 \%$, while quercetin and ranitidine were $47.0 \%$ and $62.6 \%$, respectively. In indomethacin ulcer, the effectiveness of the test substance was $49.1 \%$, quercetin showed less pronounced activity, which was 36.4 $\%$, ranitidine showed an effect of $54.5 \%$.

It is proved that the food concentrate of phenolic compounds of apples of comparison inhibits the course of lipid peroxidation reactions and supports endogenous systems of antioxidant protection. This was confirmed by a 1.6-fold decrease in the gastric homogenate of TBA reactants in the alcohol-prednisolone ulcer model and a 1.5-fold decrease in the indomethacin ulcer model. On the part of the antioxidant defence system, treatment with concentrate led to an increase in the content of reduced glutathione by 1.7 times and 2 times in the model of alcohol-prednisolone ulcer and indomethacin ulcer, respectively.

\section{Conflict of interests}

The authors declare there is no conflict of interests.

\section{Financing}

The research was performed within the framework of the initiative topic "Cellular and molecular mechanism of development and correction of pathological conditions" No. 01150000966.

References

1. Shigabutdinova, F. G. (2004). Rol fitoterapii v gastroenterologii. Alternativnaia meditsina, 3, 38-40.

2. Solodovnychenko, N. M., Zhuravlov, M. S., Kovalov, V. M. (2001). Likarska roslynna syrovyna ta fitopreparaty. Kharkiv: Zoloti storinky, 408.

3. Zalihyna, E. V., Podpletniaia, E. A. (2017). Investigation of antiulcer activity of the thick extract of immature walnut fruits under the model of indometacin-induced gastric ulcer of rats. Aktualni pytannia farmatsevtychnoi i medychnoi nauky ta praktyky, 10 (3 (25)), 324-328.

4. Kurkin, V. A. (2006). Fitoterapiia gastrita i iazvennoi bolezni. Rossiiskie apteki, 6, 12-14.

5. Zagayko, A. L., Kravchenko, G. B., Fylymonenko, V. P., Krasilnikova, O. A. (2017). Effect of apple polyphenol concentrate on lipid metabolism in rats under experimental insulin re-sistance. Wiadomości Le-karskie, 70 (2 (1)), $200-204$.

6. Zagayko, A. L., Kravchenko, G. B., Krasilnikova, O. A. (2017). Apple polyphenol extract reduces JNK phosphorylation in the liver of insulin-resistant rats. Science review, 7 (7 (7)), 11-13.

7. Zagayko, A., Briukhanova, T., Lytkin, D., Kravchenko, A., Fylymonenko, V.; Shalaby, E. (Ed.) (2019). Prospects for using the natural antioxidant compounds in the obesity treatment. Antioxidants. IntechOpen. doi: http://doi.org/10.5772/intechopen.83421

8. Stefanov, O. V. (Ed.) (2001). Doklinichni doslidzhennia likarskykh zasobiv. Kyiv: Avitsenna, 528.

9. Kamyshnikov, V. S. (2003). Kliniko-biokhimicheskaia laboratornaia diagnostika. Vol. 1. Minsk: Interpresservis, 463.

10. Glants, S. (1998). Mediko-biologicheskaia statistika. Moscow: Praktika, 459.

11. Kolisnyk, O. A., Chystiakov, O. H., Drohovoz, S. M., Pozdniakova, A. Yu. (2014). The study of the antiulcer activity of biofiton ${ }^{\circledR}$ "Healthy stomach" on acute alcohol-prednisolone stomach ulcer in rats. Klinichna farmatsiia, 3, 42-46. 
12. Zalyhina, Ye. V., Podpletnia, O. A. (2016). Screening study of antiulcer activity of thick extracts from unripe fruits of walnut. Farmakolohiia ta likarska toksykolohiia, 6 (51), 47-52.

Received date 05.08.2021

Accepted date 16.09.2021

Published date 30.09.2021

Liubov Galuzinska*, PhD, Associate Professor, Department of Biological Chemistry, National University of Pharmacy, Pushkinska str., 53, Kharkiv, Ukraine, 61002

Vira Kravchenko, Doctor of Biological Sciences, Professor, Department of Biological Chemistry, National University of Pharmacy, Pushkinska str., 53, Kharkiv, Ukraine, 61002

Ganna Kravchenko, $\mathrm{PhD}$, Associated Professor, Department of Biological Chemistry. National University of Pharmacy, Pushkinska str., 53, Kharkiv, Ukraine, 61002

Tetiana Briukhanova, PhD, Assistant, Department of Biological Chemistry, National University of Pharmacy, Pushkinska str., 53, Kharkiv, Ukraine, 61002

Victoriia Fylymonenko, PhD, Associate Professor, Department of Biological Chemistry, National University of Pharmacy, Pushkinska str., 53, Kharkiv, Ukraine, 61002

*Corresponding author: Liubov Galuzinska, e-mail: ljubvgaluzinskaja@ukr.net 